\title{
RESERVA DE DESENVOLVIMENTO SUSTENTÁVEL: AVANÇO NA CONCEPÇÃO DE ÁREAS PROTEGIDAS?
}

\section{Sustainable Development Reserve: Progress In The Protected Areas Design?}

\author{
Patrícia Pereira Mattos \\ Bióloga e Mestre em Desenvolvimento e Meio Ambiente pela UFRN \\ $\mathrm{Natal} / \mathrm{RN}-$ Brasil \\ patriciamattos@ufrnet.br \\ Itamar de Morais Nobre
}

Prof. Adjunto, Depto. de Comunicação Social, UFRN

Natal/RN - Brasil

itanobre@gmail.com

Magdi Ahmed Ibrahim Aloufa

Professor Associado, UFRN, Programa de Pós-graduação em Desenvolvimento e Meio Ambiente

$\mathrm{Natal} / \mathrm{RN}$ - Brasil

magdi-aloufa@bol.com.br

Artigo recebido em 14/07/2011 e aceito para publicação em 20/07/2011

RESUMO: $\quad$ O movimento ambiental, denominado socioambientalismo, foi pioneiro ao reconhecer a intrínseca ligação entre as questões sociais e ambientais e apresenta uma importante atuação na sociedade civil brasileira em defesa dos direitos dos povos tradicionais. A Reserva de Desenvolvimento Sustentável (RDS) é uma categoria essencialmente socioambiental, pois incorpora aos objetivos da conservação, ações de inclusão social, valorização do conhecimento local e práticas de manejo ambiental. O trabalho objetivou investigar a percepção ambiental e o nível de envolvimento da população com relação à $R D S$ Ponta do Tubarão, localizada no estado do Rio Grande do Norte. Foram realizadas entrevistas abertas e semiestruturadas $(n=262)$ e a análise de conteúdo evidenciou que a maioria dos entrevistados atribuiu importância à área protegida; todavia, constatou-se um alto nível de insatisfação com sua gestão e desconhecimento dos seus objetivos, detectaram-se inúmeros conflitos socioambientais, com destaque para proibição de construções e foram propostas alternativas para melhoria da qualidade de vida local. Esse trabalho conduz a uma reflexão da prática de gestão da área protegida estudada e espera-se que os dados obtidos possam subsidiar o plano de manejo local e minimizar os conflitos socioambientais existentes na área.

Palavras-chaves: Povos tradicionais. Percepção ambiental. Socioambientalismo.

ABSTRACT: The environmental movement, called social environmentalism, was a pioneer in recognizing the intrinsic connection between social and environmental issues and presents an important role in Brazilian civil society in defending the rights of traditional peoples. The Sustainable Development Reserve (Reserva de Desenvolvimento Sustentável RDS) is essentially a socio- environmental category, as it incorporates the objectives of conservation, actions for social inclusion, valuing local knowledge and practices of 
Reserva de desenvolvimento sustentável: avanço na concepção de áreas protegidas?

Patrícia Pereira Mattos, Itamar de Morais Nobre, Magdi Ahmed Ibraim Aloufa

environmental management. This study aimed to investigate the environmental perception and the level of the population involvement related to RDS Ponta do Tubarão, located in the state of Rio Grande do Norte. Open and semi-structured interviews $(n=262)$ were conducted and content analysis showed that most of those interviewed attributed importance to protected areas; however, a high level of dissatisfaction was noted with its management and ignorance towards their objectives; numerous environmental conflicts were detected, especially the prohibition of construction, and alternatives were proposed to improve the quality of local life. This study leads to a reflection of the management practice of protected area study and hope that this data can support the local management plan and minimize the socio-environmental conflicts in the area.

Keywords: Traditional peoples. Environmental perception. Social environmentalism.

\section{INTRODUÇÃO}

Área protegida pode ser definida como "uma área terrestre ou marinha especialmente dedicada à proteção e manutenção da diversidade biológica e dos recursos naturais e culturais associados, manejados através de instrumentos legais ou outros instrumentos efetivos" (MEDEIROS, 2006). No Brasil, o conjunto de áreas naturais protegidas, denominado unidades de conservação (UC), apresenta como principais objetivos a proteção de biomas e ecossistemas naturais, preservação de espécies raras, endêmicas ou em risco de extinção, proteção de áreas de grande beleza cênica, incentivo à pesquisa cientifica, incentivo às ações de educação ambiental e ao manejo sustentável dos recursos naturais (BRASIL, 2000; HASSLER, 2005; MEDEIROS, 2006).

Apesar das áreas protegidas serem consideradas uma ferramenta essencial para a conservação da biodiversidade e para a contenção do uso predatório dos recursos naturais, na prática vêm enfrentando inúmeras dificuldades de gestão, pois a criação dessas áreas não está sendo suficiente para assegurar a proteção dos recursos naturais e culturais. As maiores dificuldades referem-se às restrições de uso dos recursos naturais para as comunidades locais, as quais têm sido causadoras de inúmeros conflitos socioambientais (BENSUSAN, 2006; BEZERRA et al, 2008).

A origem dos atuais conflitos socioambientais é decorrente do modelo dominante de áreas protegidas criado nos Estados Unidos em meados do século XIX. Esse modelo - denominado "wilderness" - não permite a existência de moradores, pois parte do princípio de que todo ser humano é intrinsecamente destruidor da natureza. Os principais objetivos deste modelo eram preservar a vida selvagem e resguardar áreas de grande valor paisagístico. As áreas protegidas dos países de primeiro mundo eram profundamente elitistas, voltadas, sobretudo, para o homem urbano, para que este pudesse reverenciar a natureza intocada e refazer suas energias desgastadas pelo ritmo crescente do capitalismo industrial (DIEGUES, 2004). O modelo "wilderness" se espalhou rapidamente pelo mundo, reproduzindo a dicotomia entre povos e parques; todavia, sofreu severas críticas tanto dentro quanto fora dos EUA, e as críticas foram voltadas principalmente para sua inadequação aos países subdesenvolvidos, que apresentam uma grande diversidade cultural, sobretudo de populações tradicionais (ARRUDA, 1999; DIEGUES, 2004). Leff (2007) reforça essa idéia afirmando que as soluções conservacionistas dos países do Hemisfério Norte resultam inadequadas e insuficientes para compreender e resolver as problemáticas nos países do Hemisfério Sul.

No Brasil, as idéias do modelo de parque sem moradores foram contrapostas por um movimento ambiental, denominado socioambientalismo, que se consolidou nos anos 80 do século XX e apresenta uma importante atuação na esfera política da sociedade civil (LITTLE, 2002; FERREIRA, 2004). Este movimento não apresenta paralelo no ambientalismo internacional e foi construído com base na idéia de que as políticas públicas ambientais devem incluir e envolver as comunidades locais, detentoras de conhecimentos e de práticas de manejo ambientais (SANTILLI, 2005). Dentre as principais conquistas jurídicas do movimento socioambiental, temos a Cons- 
tituição Federal de 1988, com destaque para proteção dos direitos dos povos indígenas e quilombolas, e a Lei Federal $n^{\circ}$ 9.985/2000 que instituiu o Sistema Nacional de Unidades de Conservação - SNUC (SANTILLI, 2005).

O projeto de lei do Sistema Nacional de Unidades de Conservação foi debatido por dez anos no Congresso Nacional e serviu para evidenciar as acentuadas divergências entre as correntes ambientalistas, quais sejam as socioambientalistas, as conservacionistas, as preservacionistas e as ruralistas. Dentre os pontos mais polêmicos das discussões destacavam-se a questão das populações tradicionais, a participação popular no processo de criação e gestão das áreas protegidas e as indenizações para desapropriações (LITTLE, 2002; MEDEIROS, 2006).

O SNUC atendeu a estratégias distintas de gestão e as áreas protegidas foram divididas em dois grupos: "Unidades de Proteção Integral" que têm como objetivo principal a conservação da biodiversidade sem que haja interferência humana, admitindo-se apenas o uso indireto dos recursos naturais como atividades educacionais, científicas e recreativas, e "Unidades de Uso Sustentável" que objetivam compatibilizar a conservação da biodiversidade com o uso sustentável dos recursos naturais. Nesse grupo admite-se o uso direto dos recursos naturais de forma restrita e regulada (RYLANDS; BRADON, 2005; MEDEIROS, 2006). Além de organizar as áreas protegidas que se encontravam dispersas e sem objetivos definidos, o SNUC foi um instrumento que abriu espaço para que categorias socioambientais fossem incorporadas ao sistema, como foi o caso da Reserva de Desenvolvimento Sustentável, categoria que apresenta um caráter inovador, porque foi especialmente destinada a proteger os direitos das populações tradicionais, cuja existência baseia-se em sistemas sustentáveis de exploração dos recursos naturais (MEDEIROS, 2006; SANTILLI, 2005). De acordo a legislação, o objetivo básico da RDS é:

Preservar a natureza e ao mesmo tempo, assegurar as condições e os meios necessários para a reprodução e a melhoria dos modos e da qualidade de vida e exploração dos recursos naturais das populações tradicionais, bem como valorizar, conservar e aperfeiçoar o conhecimento e as técnicas de manejo do ambiente, desenvolvido por estas populações (BRASIL, 2000).

A nova concepção de áreas protegidas parte do princípio de que "a criação e manejo destas áreas deve contribuir para a redução da pobreza a nível local, ou, ao menos, não deve contribuir para criá-la ou agravá-la" (SCHERL et al. 2006). É nessa nova abordagem conservacionista que se evidencia a importância dos estudos em percepção ambiental. Esse conceito, embora possua longa trajetória na Psicologia, encontrou uma utilização mais difundida e uma maior preocupação em se determinar sua validade teórica na Geografia Humana (PACHECO, 2009). Percepção ambiental pode ser definida classicamente como:

A resposta dos sentidos aos estímulos ambientais (percepção sensorial) e a atividade mental resultante da relação com o ambiente (percepção cognitiva). Esta percepção traz aos indivíduos novos dados para a compreensão de seu entorno ao estabelecer relações como ambiente no qual está inserido (TUAN, 1980).

As pesquisas em percepção ambiental se têm mostrado úteis para compreender melhor as inter-relações entre natureza e ser humano, incorporando suas expectativas, julgamentos e condutas (CAPRA, 1996; DEL RIO; OLIVEIRA, 1996). Esses estudos têm sido empregados em diversas finalidades: ferramenta estratégica para monitorar e estimular mudanças de atitudes, sendo a base para programas de educação ambiental (SAUVÉ, 1996; MARIN et al. 2006); delineamento de estratégias para conservação de ecossistemas (ALBUQUERQUE; ALBUQUERQUE, 2005); utilização racional dos recursos naturais (WHYTE, 1978) e como um meio de compreender como os sujeitos das sociedades adquirem seus conceitos, valores, bem como se sensibilizam frente à crise ambiental (FAGGIONATO, 2002; OLIVEIRA; CORONA, 2008). Pacheco \& Silva (2005) complementam que a percepção ambiental tem sido utilizada como forma de garantir a escuta das comunidades inseridas em 
áreas protegidas e em torno destes estudos está uma sensibilidade ética que quer dar voz à população.

Esta pesquisa objetivou investigar a percepção ambiental, o nível de esclarecimento, envolvimento e satisfação da população com relação à Reserva de Desenvolvimento Sustentável, bem como reunir dados que possam fornecer subsídios para propostas do plano de manejo local. Para isso, foi empregado como estudo de caso a RDS Estadual Ponta do Tubarão, localizada no estado do Rio Grande do Norte.

No Brasil, normalmente, as áreas protegidas são criadas a partir de uma decisão unilateral (cima para baixo) por imposição do governo (SANTILLI, 2005). No entanto, a RDS Ponta do Tubarão constitui uma exceção, pois a sua criação foi uma demanda da própria população. O histórico de criação é resultado de oito anos de conflitos entre classes sociais antagônicas, onde a população se sentiu ameaçada pelo avanço do capitalismo industrial, sob a representação de investidores imobiliários e empresários da carcinicultura. A história de criação da reserva significa um movimento de ações comunitárias em defesa da preservação do território e dos seus modos de vidas tradicionais (NOBRE 2005).

\section{METODOLOGIA}

\section{Área de estudo}

A RDS Ponta do Tubarão (Figura 1) foi instituída pela Lei Estadual no 8.349/2003, e localiza-se no litoral setentrional do Rio Grande do Norte, abrangendo os municípios de Guamaré e Macau (5'2'S e $5^{\circ} 16^{\prime} \mathrm{S}$ e $36^{\circ} 23^{\prime} \mathrm{W}$ e $36^{\circ} 32^{\prime} \mathrm{W}$ ), perfazendo uma área total de 12.940,07 ha e apresentando clima semiárido, altas taxas de evaporação e média anual de $537,5 \mathrm{~mm}$ de índice pluviométrico (DIAS; SALLES, 2006). A Reserva apresenta características impares no contexto ambiental, pois abriga uma enorme diversidade de ecossistemas: porção marinha costeira, restinga, estuário, manguezais, dunas, falésias e caatinga, e está incluída entre as áreas prioritárias para a conservação da biodiversidade, sendo considerada de importância biológica muito alta (DIAS, 2006).

Figura 1: Mapa de localização da Reserva de Desenvolvimento Sustentável Ponta do Tubarão no Estado do Rio Grande do Norte.

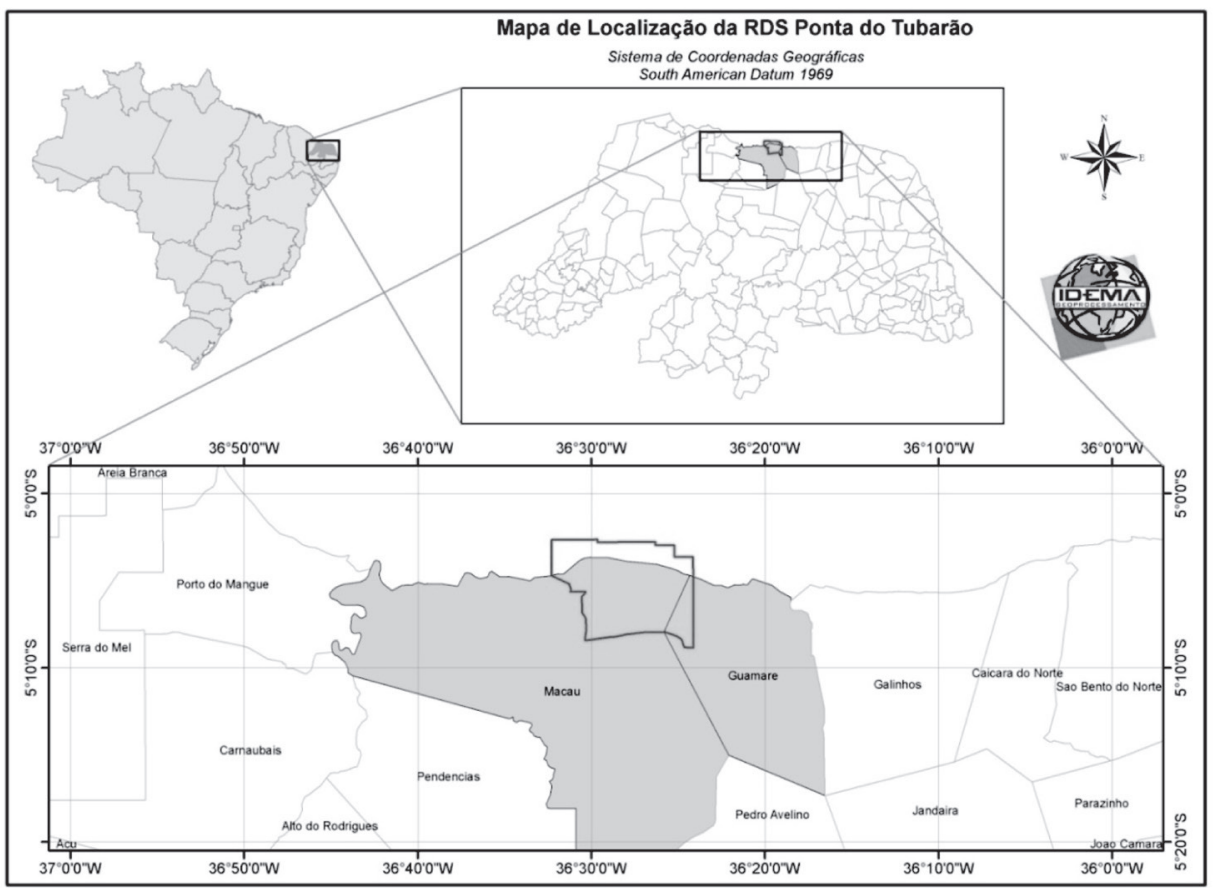

Fonte: IDEMA (2010). 
A pesquisa foi desenvolvida no município de Macau, nas comunidades de Diogo Lopes, Barreiras e Sertãozinho. Nestas, residem populações tradicionais caracterizadas pela grande dependência dos recursos naturais, conhecimento aprofundado dos ciclos naturais, pelo pertencer e apropriar-se de um território onde se reproduzem econômica, social e simbolicamente e pelo fato de permanecer e ocupar esse território por várias gerações (DIEGUES, 2001). As comunidades são bem semelhantes, em termos socioeconômicos, e garantem sua subsistência através da pesca artesanal, coleta de moluscos e crustáceos, turismo comunitário, agricultura e criação de animais, ambos em pequena escala.

A RDS Ponta do Tubarão é gerida por um conselho que atua em instância deliberativa e consultiva, presidido pelo órgão ambiental local e constituído por representantes de órgãos públicos, de organizações da sociedade civil e das populações tradicionais residentes na área. $\mathrm{O}$ conselho gestor reúne-se a cada dois meses para discutir assuntos referentes à administração da reserva e dentre suas competências destacam-se a elaboração de propostas referentes ao zoneamento ecológico econômico e o plano de manejo e gestão da reserva. $\mathrm{O}$ zoneamento tem que contemplar zonas onde se admite o uso sustentável dos recursos naturais e zonas de completa preservação dos componentes da biodiversidade. O plano de manejo deve conter tanto as normas de uso quanto o zoneamento da área (QUEIROZ; PERALTA, 2006). Além dessas atividades, o conselho gestor faz parte de grupos de trabalho para discutir assuntos específicos priorizados pelas comunidades, como pesca, uso e ocupação do solo e turismo (DIAS, 2006).

\section{PROCEDIMENTOS METODOLÓGICOS}

Os trabalhos em campo ocorreram entre os meses de maio a outubro de 2010 , com visita mensal e permanência de cinco dias durante a semana. Delimitou-se como público alvo as pessoas que trabalharam ou trabalham em atividades ligadas à pesca: pescadores, marisqueiras e catadores de caranguejo. A pesquisa recebeu aprovação do conselho gestor da reserva e apresenta o termo de consentimento assinado pelo presidente da colônia dos pescadores Z-41.
Como meio de obtenção dos dados foi utilizado o método de abordagem proposto por Whyte (1978) que se baseiam fundamentalmente na combinação de três abordagens: observar, escutar e interrogar. Foram, portanto, aplicadas entrevistas abertas e semiestruturadas. Adotou-se como universo o número de pescadores cadastrados na colônia $(n=863)$ e o tamanho da amostra, com intervalo de confiança de $5 \%$, foi de 262 entrevistados. Os entrevistados foram abordados em suas respectivas casas ou locais de trabalho, foram informados dos objetivos da pesquisa, da origem institucional do entrevistador e de que seus respectivos nomes não seriam revelados na pesquisa.

A entrevista abordou dados sociais como idade, gênero, grau de escolaridade, tempo de moradia, local de origem, profissão, tempo de trabalho e, para investigar a percepção ambiental com relação à área protegida, perguntou-se sobre o conceito de reserva ambiental, mudanças ocorridas após a implantação da reserva, grau de importância atribuída a ela e as alternativas para promoção da melhoria de qualidade de vida local.

Os dados foram avaliados pela análise de conteúdo, na qual as respostas foram submetidas a um processo de categorização temática (BARDIN, 1977). As categorias foram tabuladas no programa Excel e posteriormente convertidas em análises descritivas (percentagens). Alguns discursos foram incluídos na análise e descritos na íntegra para a melhor compreensão da realidade local.

\section{RESULTADOS E DISCUSSÃO}

\section{Aspectos sociais}

A faixa etária dos entrevistados $(n=262)$ variou dos 17 anos aos 85 anos de idade. Desse total, $74 \%$ foram pescadores, $23 \%$ marisqueiras e 3\% catadores de caranguejo. O percentual desse último representa toda a população de catadores da região, o que é considerado um percentual baixo quando comparado às outras ocupações. Alves \& Nishida (2003) ressaltam que os catadores são grupos economicamente marginais, extremamente pobres e pouco reconhecidos entre os pescadores artesanais. No presente estudo não houve equivalência entre gêneros, 
Reserva de desenvolvimento sustentável: avanço na concepção de áreas protegidas?

Patrícia Pereira Mattos, Itamar de Morais Nobre, Magdi Ahmed Ibraim Aloufa

e constatou-se que a ocupação de pescador e catador está tipicamente relacionada ao gênero masculino, enquanto que a atividade de mariscagem é típica do gênero feminino (houve registro de apenas um homem participando dessa atividade). A relação entre gênero e profissão foi compatível com os dados de Dias (2006). A média de tempo de trabalho no ofício de pescador, marisqueira e catador foi de $21,8,24,4$ e 22,5 anos, respectivamente, e a média do tempo de moradia dos entrevistados em suas respectivas comunidades foi de 32,2 anos. Marcelino et al. (2005) afirmam que o vínculo tradicional com o ambiente pode ser mais acentuado em comunidades cujo tempo de moradia ultrapassa 25 anos. Foi observado que a migração entre comunidades próximas é uma característica comum, o que também foi constatado por Begossi et al. (2009) em comunidades caiçaras, sobre as quais afirmam ser esse processo relevante para própria sobrevivência do grupo, representando uma fonte de variação e diversificação cultural. Assim como ocorreu em outros estudos realizados junto a moradores de áreas protegidas (TORRES et al. 2009; LUCENA; FREIRE, 2011) a maioria dos entrevistados $(63,3 \%)$ apresentou escolaridade referente ao ensino fundamental, e os três níveis mais representativos foram o ensino fundamental I incompleto (34\%), analfabetos $(19 \%)$ e alfabetizados (11,5\%). Também foi observada uma hierarquia de escolaridade entre os entrevistados, sendo que a marisqueira se destacou com o maior nível de escolaridade, seguida do pescador e catador de caranguejo. Alves; Nishida (2003) explicam que o baixo grau de escolaridade das comunidades pesqueiras está relacionado ao contexto social e econômico em que elas estão inseridas, no qual se incentiva o abandono escolar e a precoce inserção no mercado de trabalho. Nesse estudo, percebeu-se que essa situação pode ser mais grave entre os homens.

\section{Conceito de "Reserva Ambiental"}

A definição do conceito Reserva de Desenvolvimento Sustentável ou "Reserva ambiental", como normalmente é denominado localmente, não foi igualitária: 70,2\% afirmaram "não sei" ou deram respostas sem coerência e 29,8\% afirmaram que sabiam conceituar. Dias
(2006), em estudo realizado na área, também encontrou um percentual elevado de marisqueiras que não souberam definir a reserva, enquanto Torres et al. (2009) constataram que 50\% dos entrevistados desconhecem que residem no interior de uma área protegida.

Foi comum o registro de insatisfações dos entrevistados, mesmo ao afirmar que desconhecem o conceito de reserva: (17) "Não sei o que é reserva ambiental, pra mim é só fazer raiva a gente, porque eles não deixam mais tirar a madeira do mangue, antes as casas eram tudo de taipa, e nunca acabou por causa disso" (informação verbal). Em alguns casos, o conceito de RDS foi descrito de forma compatível a legislação; todavia, essa resposta não foi representativa, sendo restrita aos entrevistados que representam o conselho gestor.

(53) "A reserva ambiental é uma unidade de conservação onde ela é praticamente intocável, onde só pode tirar fotos, pesquisar, essas coisas assim, praticamente ninguém pode tirar nada que venha a comprometer os recursos. A de desenvolvimento sustentável pode algumas coisas, mas desde que seja de forma controlada" (informação verbal).

Houve relatos que comprovam a estreita relação do ser humano com a natureza, em contraste com a sociedade urbano-industrial: (54) "Ela é criada [reserva] primeiro que tudo pra se ter um ambiente sadio, tendo um ambiente sadio, temos uma saúde boa" (informação verbal). A maioria do segundo grupo correlacionou "reserva ambiental" à conservação de biomas e ecossistemas. A frase a seguir foi bem representativa nesse sentido: (224) "A reserva é pra não destruir os mangues e as dunas" (informação verbal). Poucos entrevistados fizeram uma correlação entre reserva e melhoria da qualidade de vida local, comprovando que há uma necessidade de se esclarecer para as comunidades os reais objetivos da Reserva de Desenvolvimento Sustentável. 


\section{IMPORTÂNCIA ATRIBUÍDA À RESERVA}

Para Vargas (2007) a base dos conflitos socioambientais resulta do produto de diferentes percepções, valores e interesses das comunidades ou grupos envolvidos. No caso da RDS Ponta do Tubarão, constatou-se uma acentuada diferença de percepções na população e, por conseguinte, conflitos socioambientais. Os principais conflitos evidenciados no local foram entre a população e órgão ambiental local e entre os próprios membros da população, pois a comunidade em geral não se sente representada pelos membros do conselho gestor.

As opiniões sobre a importância da reserva foram bem diversas, mesmo se tratando de uma população aparentemente homogênea. Os níveis de importância foram agrupados nas seguintes categorias: muito importante $(12,2 \%)$, importante $(30,2 \%)$, medianamente importante $(9,2 \%)$, pouco importante (4,2\%), nenhuma importância $(17,9 \%)$ e não sabe (26,3\%). Foram identificados indivíduos que desconhecem a importância da reserva, como também não demonstram interesse em se integrar ao assunto, como pode ser observada na reposta de uma marisqueira: (163) "Não sei dizer se é importante, eu escuto por alto que num é todo mundo que aprova não, não me informo muito porque sou muito ocupada" (informação verbal). $\mathrm{O}$ grupo que se enquadrou nas categorias muito importante ou importante é constituído de pessoas envolvidas com a reserva, que normalmente participam das reuniões realizadas na sede e cujo nível de satisfação pode ser dado por diferentes motivos:

(126) “A reserva é muito importante até porque eu tenho dois filhos, que no futuro vai precisar que aqui esteja preservado" (informação verbal).

(12) "Os italianos queriam se apossar daqui e não conseguiram. A importância da reserva é pra proteger a pesca" (informação verbal).

(21) "Se não fosse a reserva, aqui já tava coberto de viveiro de camarão" (informação verbal).

Na outra vertente, há o grupo que se posiciona de forma negativa à área protegida:
(128) “A reserva não tá ajudando o pescador" (informação verbal).

(209) "Daqui a pouco ninguém vai poder tirar mais, um búzio, um siri, por causa dessa tal de reserva" (informação verbal).

É interessante ressaltar que apesar das discordâncias com relação à reserva, $42,4 \%$ dos entrevistados consideraram a reserva como importante ou muito importante. Esse fato corrobora com alguns trabalhos (SILVA et al. 2009; LUCENA; FREIRE, 2011) e comprova que as comunidades não são contrárias a área protegida e sim à sua forma de gestão.

\section{MUDANÇAS NA COMUNIDADE}

Constataram-se acentuadas mudanças no cotidiano dos moradores após estabelecimento da reserva: $55,7 \%$ dos entrevistados atribuíram mudanças de conotação negativa, $28,7 \%$ mudanças positivas (Tabela 1) e 15,6\% afirmaram não saber ou optaram por não tomar posicionamento. As normas de uso da área e recursos são assuntos amplamente discutidos no conselho gestor; no entanto, as restrições de usos ainda são baseadas na legislação de âmbito federal, pois o plano de manejo da reserva não foi concluído e o zoneamento ainda encontra-se em fase preliminar. É importante ressaltar que um plano de manejo cientificamente embasado não é garantia de efetividade na conservação da unidade (QUEIROZ; PERALTA, 2006). A efetividade da conservação é aumentada quando os responsáveis pela administração incorporam as perspectivas e necessidade da população residente, e isso é válido tanto para as unidades de uso sustentável, quanto para as unidades de proteção integral (SILVA et al. 2009). 
Reserva de desenvolvimento sustentável: avanço na concepção de áreas protegidas?

Patrícia Pereira Mattos, Itamar de Morais Nobre, Magdi Ahmed Ibraim Aloufa

Tabela 1: Percepção local das mudanças após estabelecimento da Reserva

\begin{tabular}{cc}
\hline Mudanças positivas & $\%$ \\
\hline Diminuição do lixo & 6,1 \\
Melhorias para a comunidade & 5,2 \\
Proibição das construções & 5,8 \\
Diminuição corte mangue & 7,4 \\
Proibição viveiro de camarão & 1,6 \\
Maior fiscalização aves e crustáceos & 1,0 \\
Incentivo à pesca artesanal & 1,6 \\
\hline Mudanças negativas & $\%$ \\
\hline Nenhuma & 11,7 \\
Falhas na fiscalização & 6,5 \\
Proibição das construções & 30,4 \\
Proibição do corte do mangue & 7,1 \\
\hline
\end{tabular}

Fonte: Dados da pesquisa, 2010.

Dentre as principais mudanças sentidas pela população destacam-se os usos das plantas de mangue. Essas plantas são utilizadas pela população para diversas finalidades (lenha, ração para animais, construção de embarcações, remédio) e, apesar de ser considerada uma atividade tradicional, o órgão ambiental decretou uma norma de restrição de uso, e essa decisão dividiu opiniões. Apesar dos valores percentuais dos entrevistados que são contra e a favor do uso do mangue ter sido semelhante para o questionamento "mudanças na comunidade", os discursos dos entrevistados que são contra essa norma foram carregados de sentimento de forte insatisfação: (184) "Antigamente o mangue servia pra muita coisa, dá folha pra o gado, hoje não serve mais por causa da reserva" (informação verbal).

As mudanças positivas que se destacaram foram: diminuição do lixo, proibição das construções e melhorias para a comunidade. As "melhorias" a que os entrevistados se referiram foram as que proporcionaram maior visibilidade para a região, como encontros ecológicos, regatas de vela e palestras envolvendo temáticas sobre meio ambiente. A menor frequência de respostas com conotação positiva, e não menos importantes, foram: incentivo à pesca artesanal, maior fiscalização de aves e crustáceos e proibição de viveiros de camarão. É válido destacar que a proibi- ção dos viveiros foi citada exclusivamente pelo grupo de catadores de caranguejo. Neste caso, observou-se um reflexo positivo direto no cotidiano desse grupo, conforme a fala do catador: (13) "Se não fosse o IBAMA, o IDEMA para proibir isso [carcinicultura], acho que aqui não tinha mais nem um caranguejo" (informação verbal).

Com relação às respostas de conotação negativa, tem-se a resposta "nenhuma" como uma fonte de insatisfação, pois os entrevistados afirmaram que não ocorreram melhorias para a comunidade na forma como foi prometida ou esperada. As queixas sobre as falhas na fiscalização foram referentes à fiscalização do órgão ambiental com relação aos pescadores de outras localidades que usufruem dos recursos da região de forma predatória. As queixas mais frequentes foram voltadas para os pescadores de lagosta.

A proibição de construções foi a mudança mais representativa, ela, portanto, é a principal causadora de conflito socioambiental da reserva. Esse mesmo conflito também se destacou em um estudo realizado junto a 67 áreas protegidas de uso indireto (DIEGUES, 2001). Com relação a esse conflito, é válido ressaltar que, embora exista a necessidade de conter o avanço das construções irregulares, é preciso buscar alternativas para minimizar os problemas que a população vem enfrentando no cotidiano decorrente dessa 
restrição. Na fala do entrevistado, a seguir, observa-se que ele reconhece a necessidade de conservação da natureza, porém relata de forma bastante apropriada sua necessidade de construir um espaço como ponto de apoio para as pescarias e beneficiamento do pescado (localmente denominado rancho).

(126) "O lado bom da reserva é porque tá protegendo o meio ambiente. A falha que eu acho é proibir de fazer um rancho, eu tenho muito material caro e pesado (lâmpada, botijão, colete) que fica ruim ter que ficar subindo toda dia com ele até a minha casa. Um rancho de taipa, não pode porque eu não posso tirar mangue, o de tijolo também é proibido na beira da praia. Orancho que eles querem é de palha e aberto, mas quem vai vigiar o material para não roubar?" (informação verbal).

Nem todos apresentam o nível de consciência ambiental como o entrevistado acima, como pode ser constatado na seguinte frase: (137) "O que eu não concordo da reserva é porque prejudica de fazer as casas, casa não tem nada a ver com meio ambiente" (informação verbal). Com esse relato, sugere-se a implantação de programas de educação ambiental destinados à comunidade em geral, visando esclarecer o impacto ambiental decorrente das construções nos ecossistemas. Os entrevistados também demonstraram descontentamento com relação à aplicação das leis ambientais, alguns relataram que as mesmas não são aplicadas de forma igualitária, como pode ser comprovado pelo depoimento: (221) “A lei não serve pra todo mundo, pra o mais rico alivia as leis, já o pobre não pode nem botar um tijolo" (informação verbal).

\section{SUGESTÕES PARA MELHORIADA QUALIDA- DE DE VIDA LOCAL}

A formação de um compromisso entre populações locais e as ações de conservação só se atinge por meio do estabelecimento de uma clara relação entre a conservação dos recursos naturais e a melhoria da qualidade de vida da população (QUEIROZ; PERALTA, 2006). De acordo com a percepção dos entrevistados, a melhoria da qualidade de vida local está relacionada à resolução de problemas sociais $(56,5 \%)$, à melhoria nas condições de pesca $(36 \%)$ e a assuntos relacionados à gestão da reserva $(5,4 \%)$ (Tabela 2).

Tabela 2: Percepção para promoção da qualidade de vida local.

\begin{tabular}{cc}
\hline \hline Reserva & $\%$ \\
\hline Projetos que resgatem confiança na reserva & 1,5 \\
Esclarecimentos sobre a reserva & 1,8 \\
Aumentar fiscalização com pessoas de fora & 1,2 \\
Continuar impedir construções inadequadas & 0,3 \\
Deixar de ser reserva & 0,6 \\
\hline Pesca & $\%$ \\
\hline Criação da cooperativa de pescadores & 19,9 \\
Melhoria nas condições de trabalho & 11,2 \\
Melhoria nas condições de navegação & 4,8 \\
\hline Questões sociais & $\%$ \\
\hline Policiamento & 18,7 \\
Saúde & 13,3 \\
Emprego & 8,8 \\
Outros (saneamento, água, lixo) & 4,5 \\
\hline
\end{tabular}

Fonte: Dados da pesquisa, 2010. 
Reserva de desenvolvimento sustentável: avanço na concepção de áreas protegidas?

Patrícia Pereira Mattos, Itamar de Morais Nobre, Magdi Ahmed Ibraim Aloufa

Os esforços conservacionistas devem estar dirigidos aos problemas socioeconômicos das populações que dependem diretamente da biodiversidade. Portanto, os custos da conservação não devem ser restritos à fiscalização dos recursos naturais - deve-se atuar em investimentos sociais, econômicos e culturais que beneficiem as populações tradicionais (HANAZAKI, 2003; DIEGUES, 2004).

Para uma melhor gestão da reserva, os entrevistados sugerem esclarecimentos sobre a área protegida e a realização de projetos que resgatem a confiança no povo. Essas respostas refletem a necessidade de mediadores para que possam interceder em situações de conflito, bem como oferecer medidas compensatórias às restrições de usos determinadas pelo plano de manejo. Queiroz; Peralta (2006) destacam as medidas compensatórias propostas pela RDS Mamirauá, no estado do Amazonas: valorizar os produtos da biodiversidade local no mercado, agregar valor a estes produtos, impedir a diminuição da renda local, tipicamente baixa, em decorrência do acatamento das normas de manejo, promover uma correlação direta entre geração de renda e conservação, com amplas implicações educativas e demonstrativas e sempre que possível aumentar a geração de renda por meio de mecanismos não impactantes.

Com relação às condições de melhoria de pesca destacou-se a criação de uma cooperativa de pescadores. Para Nobre (2005) e Dias (2006), a cooperativa iria minimizar sérios problemas, como desvalorização e descarte do pescado decorrente da falta de mercado consumidor. Também foram citadas necessidades para melhoria das condições de trabalho, como aquisição de canoas e frigoríficos, e melhorias nas condições de navegação, como iluminação e dragagem.

Nas comunidades estudadas, constatou-se que os serviços públicos de segurança e saúde são precários. Na percepção dos entrevistados, a presença da polícia poderia minimizar o consumo de drogas e seus problemas decorrentes. Com relação à saúde, a queixa principal foi ausência de médico para atendimento em caráter de urgência. Outras queixas foram a respeito do Poder Público Municipal, em alguns relatos afirmou-se que a negligência da Prefeitura com as comunidades aumentou depois que o local passou a ser reserva. $O$ cotidiano desses moradores representa o modelo predominante de conservação do Brasil, onde as agências governamentais negligenciam a realidade dos usuários e criam as regras baseando-se apenas no sistema ecológico (BEGOSSI et al. 2009).

\section{CONSIDERAÇÕES FINAIS}

A RDS Ponta do Tubarão apresentou, no ato da criação, uma boa atuação na conservação dos ecossistemas naturais ao inibir iniciativas de grande impacto ambiental, como a especulação imobiliária e a carcinicultura. No entanto, precisa rever estratégias de gestão para conciliar a conservação biológica e cultural. O nível de envolvimento da população com a área protegida diminuiu consideravelmente, pois a maioria não conseguiu perceber melhorias concretas para suas comunidades.

A análise de conteúdo evidenciou que os moradores necessitam de esclarecimentos acerca dos propósitos e objetivos da área protegida; igualmente comprovou que a maioria considera a importância da reserva. Entretanto, constatou-se um alto nível de insatisfação com sua gestão. Torna-se necessário o delineamento de estratégias que conduzam a população a uma percepção positiva da área protegida, pois esta deve ser vista como um meio capaz de proporcionar o aumento da qualidade de vida local. Para os entrevistados, a melhoria da qualidade de vida local está fortemente vinculada à criação da cooperativa dos pescadores e à resolução dos problemas sociais. Essas reivindicações deverão ser atendidas em caráter prioritário através de uma maior articulação entre as esferas governamentais e, para isso, sugere-se vincular o nome da reserva a essas ações, para que a área protegida estudada ganhe visibilidade social.

É importante ressaltar que não se pode questionar o avanço que se processou no Brasil, com o sistema nacional de unidade de conservação (SNUC) e com relação aos marcos legais conquistados pelo movimento socioambiental. No entanto, este trabalho, conduz a uma reflexão sobre a prática de gestão de uma área protegida com caráter inovador no SNUC e reforça que é necessário que os tomadores de decisão da área protegida estudada se aproximem da realidade dos moradores, levem em consideração o conheci- 
mento e a percepção da comunidade local e analisem os fatos de forma participativa, conforme previsto pela legislação.

\section{AGRADECIMENTOS}

Nós agradecemos aos moradores da reserva pela preciosa colaboração no trabalho, ao órgão ambiental local, que concedeu autorização da pesquisa e a casa do pesquisador, e à CAPES pela concessão da bolsa de mestrado para a primeira autora.

\section{REFERÊNCIAS}

ALBUQUERQUE, C. A; ALBUQUERQUE, U. P. Local perceptions towards biological conservation in the community of vila velha, Pernambuco, Brazil. Interciencia. Caracas. v. 30, n. 8, p. 460-465, 2005.

ALVES, R. R. N.; NISHIDA, A. K. Aspectos socioeconômicos e percepção ambiental dos catadores de caranguejo-uçá Ucides cordatus cordatus (L. 1763) (Decapoda, Brachyura) do Estuário do Rio Mamanguape, Nordeste do Brasil. Interciencia. v. 28, p. 36-43. 2003.

ARRUDA, R. Populações tradicionais e a proteção dos recursos naturais em unidade de conservação. Ambiente \& Sociedade, Campinas, v. 2, n.5, p. 79-92, 1999.

BARDIN, L. Análise de Conteúdo. 3. ed. Lisboa: Edições 70, 1977. 223 p.

BEGOSSI, A. et al. Ecologia de pescadores artesanais da Baía da Ilha Grande. São Carlos: Editora Rima, 2009. $261 \mathrm{p}$.

BENSUSAN, N. Conservação da biodiversidade em áreas protegidas. Rio de Janeiro: FGV, 2006. 176 p.
SEPPE, Â. G. C. Percepção ambiental de alunos e professores do entorno da Estação Ecológica de Caetés - Região Metropolitana do Recife-PE, Biotemas, Florianópolis, v. 21, p. 147-160, 2008.

BRASIL. Lei federal nº995, de 18 de junho de 2000. Institui o Sistema Nacional de Unidade de Conservação. Disponível em: http://www.socioambiental.org/ website/noticias/naintegra/docs/snuc.html. Acesso em: 13 ago. 2010.

CAPRA, F. A Teia da Vida: uma nova compreensão científica dos sistemas vivos. São Paulo: Cultrix, 1996. $256 \mathrm{p}$.

DEL RIO, V.; OLIVEIRA, L. (orgs). Percepção Ambiental. São Paulo, São Carlos: Studio Nobel, 1996.

DIAS, T. L. P ; SALLES, R. Diagnóstico da pesca artesanal e proposta de plano de ordenamento da pesca na reserva de desenvolvimento sustentável Ponta do Tubarão (Macau Guamaré/RN): relatório técnico IDEMA. 2006. 106 p.

DIAS, T. L. P. Os peixes, a pesca e os pescadores da Reserva de Desenvolvimento Sustentável Ponta do Tubarão (Macau-Guamaré/RN) Brasil. 2006. 167 f. Tese (Doutorado em Zoologia). Centro de Ciências Exatas da Natureza, Universidade Federal da Paraíba, João Pessoa, 2006.

DIEGUES, A. C. S. As populações humanas em áreas naturais protegidas da Mata Atlântica. In: Ecologia Humana e Planejamento Costeiro. São Paulo: NUPAUB, 2001. p.169-184.

DIEGUES, A.C. S. O mito moderno da natureza intocada. 4. ed. São Paulo: Hucitec. 2004. 169 p.

BEZERRA, T. M. O.; FELICIANO, A. L. P.; GIU- 
Reserva de desenvolvimento sustentável: avanço na concepção de áreas protegidas?

Patrícia Pereira Mattos, Itamar de Morais Nobre, Magdi Ahmed Ibraim Aloufa

FAGGIONATO, S. Percepção ambiental. 2002. Disponível em: http://www.educar.sc.usp.br. Acesso em: 10. dez. 2010.

FERREIRA, L. C. Dimensões humanas da biodiversidade: mudanças sociais e conflitos em áreas protegidas no Vale do Ribeira, SP, Brasil. Ambiente \& Sociedade, Campinas, v.7, n.1, p.47-66. 2004.

HASSLER, M. L. A importância das unidades de conservação do Brasil. Sociedade \& Natureza, Uberlândia, v. 17, n. 33, p. 79-89, 2005.

HANAZAKI, N. Comunidades, conservação e manejo: o papel do conhecimento ecológico local. Biotemas. Florianopólis: [S.1.], v.16, n. 1, p. 23-47, 2003.

LEFF, E. Interdisciplinaridade, Ambiente e Desenvolvimento Sustentável. In: Epistemologia ambiental. São Paulo: Cortez, 2007, p. 61-108.

LITTLE, P. Territórios sociais e povos tradicionais no Brasil: por uma antropologia da territorialidade. 2002. Disponível em: http://visites.unb.br/ics/dan/Series322. Acesso em: 07 jul. 2010.

LUCENA, M. M. A.; FREIRE, E. M. X. Percepção Ambiental sobre uma Reserva Particular do Patrimônio Natural (RPPN), pela Comunidade Rural do Entorno, Semiárido brasileiro. Educação ambiental em ação. n. 35, mar./mai. 2011. Disponível em: < http://www.revistaea.org/>. Acesso em: 02 mai. 2011.

MARCELINO, R. L. et al. Uma abordagem sócio-econômica e sócio-ambiental dos pescadores artesanais e outros ribeirinhos do estuário do Rio Paraíba do Norte, Estado da Paraíba, Brasil. Tropical Oceanography, v. 33, p. 179-192, 2005.
MARIN, A. A.; OLIVEIRA, T. H.; COMAR, V. A Educação ambiental num contexto de complexidade no campo teórico da percepção. Interciencia, v. 28, n. 10, p. 616-619, 2006.

MEDEIROS, R. Evolução das tipologias e categorias de áreas protegidas no Brasil. Ambiente \& Sociedade, Campinas, v. 9, n. 1, p. 41-64, 2006.

NOBRE, I. M. Revelando os modos de vida de ponta do tubarão. 2005. 260 f. Tese (Doutorado em Ciências Sociais)- Programa de Pós-Graduação em Ciências Sociais, Centro de Ciências Humanas, Letras e Artes, Universidade Federal do Rio Grande do Norte, Natal. 2005.

OLIVEIRA, K. A.; CORONA, H. M. P. A percepção ambiental como ferramenta de propostas educativas e de políticas ambientais. Anap Brasil. v. 1, n. 1, p. 53-72, 2008.

PACHECO, E. T. Percepção ambiental como desvelamento do ethos embrionário. 2009. $279 \mathrm{f}$. Tese (Doutorado em Psicossociologia de Comunidades e Ecologia Social)- Instituto de Psicologia, Universidade Federal do Rio de Janeiro, Rio de Janeiro, 2009.

PACHECO, E. ; SILVA, H. P. Compromissos epistemológicos do conceito de percepção ambiental. In: CONGRESSO DE ECOLOGIA DO BRASIL, 7. 2005, Caxambu,

MG. Disponível em: http://www.ivt-j.net/sapis/2006/pdf/ EserPacheco.pdf . Acesso em: 09 abr. 2010.

QUEIROZ, H. L; PERALTA, N. Reserva de Desenvolvimento Sustentáveis: manejo integrado dos recursos naturais e gestão participativa. In: GARAY, I.; BECKER, B. K. (Org.) Dimensões Humanas da Biodiversidade: o desafio de novas relações Sociedade-Natureza no Século XXI. Petrópolis: Vozes. 2006. p. 447-473 
RYLANDS, B. A.; BRADON, K. Unidades de conservação brasileiras. Megadiversidade. Belo Horizonte. v. 1, n. 1, p. 27-35, 2005.

RIO GRANDE DO NORTE. Lei Estadual $n^{\circ} 8.349$, de 17 de julho de 2003. Disponivel em:

$<\mathrm{http} / /$ www.gabinetecivil.rn.gov.br $>$. Acesso em: 09 jul. 2010.

SAUVÉ, L. Environmental education and sustainable development: a further appraisal. Canadian Journal of Environmental Education, v. 1, n. 1, 1996, p.7-34.

SANTILLI, J. Sociambientalismo e novos direitos: proteção jurídica à diversidade biológica e cultural. São Paulo: Petrópolis, 2005. 303 p.

SCHERL, L. M. et al. As áreas protegidas podem contribuir para a redução da pobreza: oportunidades e limitações. Reino Unido: IUCN, 2006. 60 p.

SILVA, T. S.; CANDIDO, G. A.; FREIRE, E. M. X. Conceitos, percepções e estratégias para conservação de uma Estação Ecológica da caatinga nordestina por populações do seu entorno. Sociedade \& Natureza, Uberlândia, v. 21, n. 2, p. 23-37, 2009.

TORRES, D. F et al. Etnobotânica e etnozoologia em unidades de conservação: uso da biodiversidade na APA de Genipabu, Rio Grande do Norte, Brasil. Interciencia. [S.1.], v. 34, p. 623-629. 2009.

TUAN, Y. Topofilia: um estudo da percepção, atitudes e valores do meio ambiente. São Paulo: Difel, 1980. $288 \mathrm{p}$.

VARGAS, G. M. Conflitos sociais e sócio-ambientais: proposta de um marco teórico e metodológico. Sociedade \& Natureza, Uberlândia, v. 19, n. 2, p.191-203, 2007.
WHYTE, A. V. T. La perception de L'environment: lignes directrices méthodologiques pour les etudes sur le terrain. Paris: UNESCO, 1978. 143 p. 
